\title{
Poly(phenylacetylene) Amines: A General Route to Water- Soluble Helical Polyamines
}

Esteban Suárez-Picado, Emilio Quiñoá, Ricardo Riguera, Félix Freire

\section{Accepted Manuscript}

This is the Accepted Manuscript version of a Published Work that appeared in final form in Chemistry of Materials, Copyright (c) 2018 American Chemical Society after peer review and technical edityng by the publisher. To access the final edited and published work see: https:// pubs.acs.org/doi/10.1021/acs.chemmater.8b03238

\section{How to cite:}

Suárez-Picado, E., Quiñoá, E., Riguera, R., \& Freire, F. (2018). Poly(phenylacetylene) Amines: A General Route to Water-Soluble Helical Polyamines. Chemistry Of Materials, 30(19), 6908-6914. doi: 10.1021/acs.chemmater.8b03238

\section{Copyright information:}

(C) 2018 American Chemical Society 


\title{
Poly(phenylacetylene) amines: A general route to water soluble hel- ical polyamines
}

\author{
Esteban Suárez-Picado, Emilio Quiñoá, Ricardo Riguera* and Félix Freire.* \\ Centro Singular de investigación en Química Biolóxica e Materiais Moleculares (CiQUS) and Departamento de Química \\ Orgánica, Universidade de Santiago de Compostela, E-15782 Santiago de Compostela, Spain.
}

\section{Supporting Information Placeholder}

\begin{abstract}
Polyphenylacetylenes bearing prim- and secamine groups are barely known due to their poisoning activity towards the polymerization catalyst. Herein we prepare 11 different amino polymers in high yields by direct polymerization of their corresponding ammonium salts in water using $\left[\mathrm{Rh}(\operatorname{cod})_{2}\right]^{+} \mathrm{BF} 4^{-}$as catalyst. They are stable, water soluble, and show a helical structure that responds to external stimuli (polarity, $\mathrm{pH}$ and metal ions) acting on the pendants. The location of the amino group in the pendant is shown to be critical for the helical response to protonation.
\end{abstract}

\section{INTRODUCTION}

Poly(phenylacetylene) $\mathrm{s}^{1-9}$ (PPAs) are a family of dynamic helical polymers ${ }^{10-15}$ where the helical sense, ${ }^{16-20}$ elongation of the helical scaffold ${ }^{21}$ or even both, ${ }^{22-23}$ can be tuned by the action of different external stimuli such as temperature, polarity of the solvent, chiral additives or metals among others. This property makes these materials very interesting in sensing, ${ }^{24-25}$ chiral separations ${ }^{26}$ or asymmetric synthesis, ${ }^{27-28}$ fields where the helical scaffold and its characterization, are vital.

In helical polymers, the typical structure elucidation techniques used for proteins or foldamers do not work due to the presence of a monomer-repeating unit along the polymer chain. Thus, to obtain information about the different structural parameters of the helices, several research groups have worked during the last decade on different structural techniques. Pioneering works made use of AFM and X-Ray, ${ }^{29-32}$ and were described by Yashima's and Percec's groups. Those efforts were followed by the introduction of $\mathrm{NMR}^{33}$ and $\mathrm{DSC}^{34}$ techniques by Tabata's and Aoki's laboratories that provided additional structural information on these materials. Quite recently, our group has demonstrated that a combination of theoretical and experimental CD and VCD studies provides reliable information about the different helical senses adopted by the PPAs. ${ }^{35-36}$ Therefore, the combined use of those different techniques allow us to obtain a good approximation to the secondary structure of PPAs even when they are constituted by an equilibrium mixture of different helices. ${ }^{37}$

Hence, PPAs could be great candidates to mimic helical biomolecules and their interactions. Nevertheless, the lipophilic character of most of these polymers and the difficulties to prepare water soluble PPAs have always represented an obvious limitation.

In the literature there are only a few examples dealing with water soluble PPAs. ${ }^{38-41}$ The main problem is that the typical $\mathrm{Rh}(\mathrm{I})$ catalyst gets poisoned in the presence of polar groups such as primary amines. ${ }^{42-44,49}$ A protection/deprotection approach has been used $^{48-49}$ but in addition to the obvious increase in the number of synthetic steps, it is not easy to find experimental conditions for the total disappearance of the protecting groups without affecting the integrity of the polymer.

Tang and coworkers gave a step forward to surpass this problem by using $[\mathrm{Rh}(\mathrm{nbd}) \mathrm{Cl}]_{2}, \quad[\mathrm{Rh}(\operatorname{cod}) \mathrm{Cl}]_{2}$ and $\mathrm{Rh}^{+}(\mathrm{nbd})-\left[\mathrm{C}_{6} \mathrm{H}_{5} \mathrm{~B}^{-}\left(\mathrm{C}_{6} \mathrm{H}_{5}\right)_{3}\right]$ as catalyst to polymerize phenylacetylenes (PAs) bearing carboxylic acid or alcohol groups. ${ }^{42-43}$ On the other hand, in case of phenylacetylenes bearing amino groups as polar groups, Yashima and coworkers were able to prepare PPAs based on tertiary amines, ${ }^{50-52}$ but unfortunately, no conditions were found for an effective polymerization of phenylacetylenes bearing primary and secondary amino groups. Only very low or moderate yields have been reported for this family of PPAs. ${ }^{42-44,49}$

In this paper, we will show that an effective, rapid, high yield and stereoregular polymerization of phenylacetylenes (PAs) bearing prim- and sec-amine groups can be carried out in water with $\left[\mathrm{Rh}(\operatorname{cod})_{2}\right]{ }^{+} \mathrm{BF} 4-$ as catalyst, using the most elemental way of protection for amino groups: its protonated form. 
This protocol allows the preparation of a large variety of PPAs bearing primary or secondary amino groups so far inaccessible. In addition, along this manuscript their stability, helical properties and response to some external stimuli will be also described.

\section{RESULTS AND DISCUSSION}

Polymer synthesis. A library of phenylacetylene amines 1-11 (Figure 1a) was used for these studies. Monomers 1-7 were prepared by coupling 4-ethynylaniline 11 with the carboxylic group of aminoacids Gly (1), Ala (2), Val (3), Leu (4), Ile (5), Phe (6) and Pro (7). Monomers 8-10 were obtained by coupling the carboxylic group of 4ethynylbenzoic acids with the methyl esters of Dap (8), Orn (9) and Lys (10). Moreover, ethynylaniline 11 was also incorporated to the collection (see SI for details).

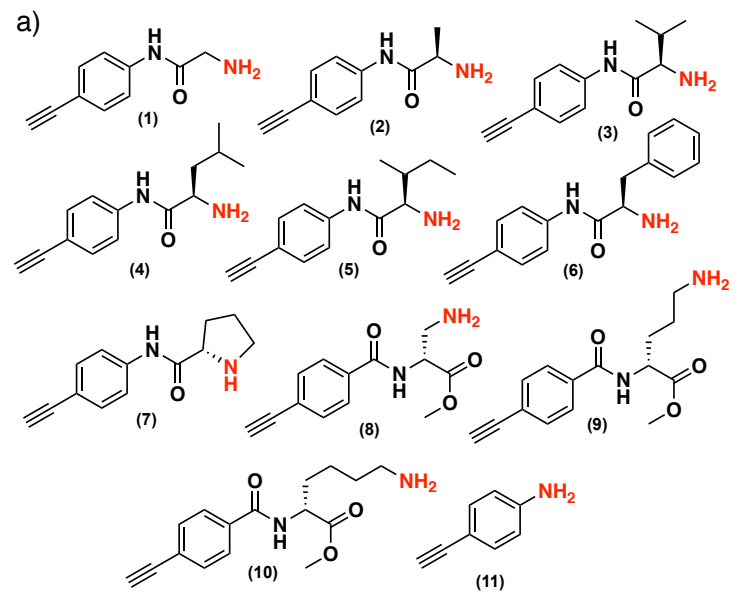

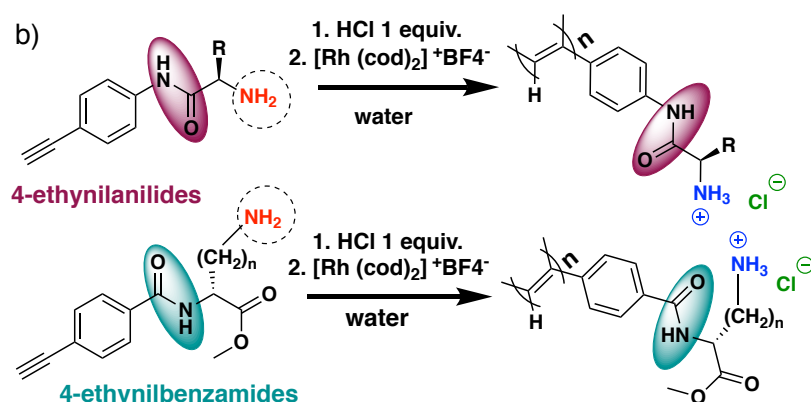

c)

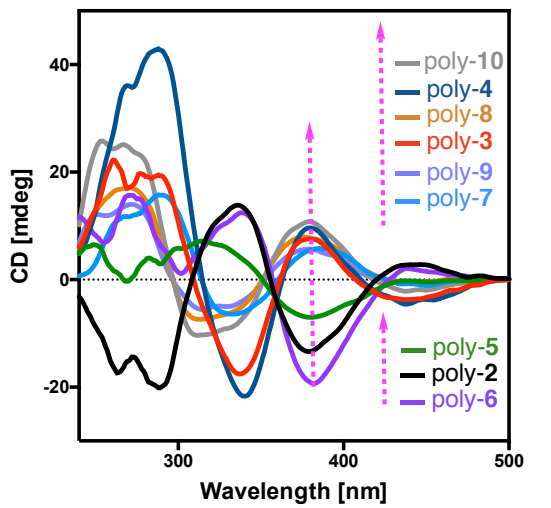

Figure 1. (a) Structure of monomers 1-11. (b) Polymerization conditions of phenylacetylenes bearing primary amines. (c) CD spectra of [poly-(2-10)- $\left.\mathrm{H}^{+}\right]$in water $(\mathrm{pH}=$ 4.5). [amino-PPA] $=0.5 \mathrm{mg} / \mathrm{mL}$

To carry out the polymerization, the monomers were dissolved in water, protonated by addition of 1 equiv. of $\mathrm{HCl}$, and then, $\left[\mathrm{Rh}(\mathrm{cod})_{2}\right]^{+} \mathrm{BF} 4^{-}$was added as catalyst (Figure 1b). The conversion of monomers 1-11 into polymers, poly-(1-11)- $\left(\mathrm{H}^{+}\right)$, occurs in high yields $(60-$ $90 \%$, Table 1), producing stereoregular PPAs with a high cis content of double bonds as determined by ${ }^{1} \mathrm{H}-\mathrm{NMR}$ (vinyl proton: 5.6-5.8 ppm) and Raman spectroscopy (see Figures S31-S41).

When the polymerization reaction was carried out on the free amines 1-11 (without previous protonation), no evidence of poly-(1-11) was observed (See Table S3).

Amino-PPA properties. [poly(1-11)- $\mathrm{H}^{+}$] PPAs showed a good solubility in water (up to $40 \mathrm{mg} / \mathrm{mL}$ ). Moreover, those PPAs bearing chiral amino pendant groups [poly(2-10)] presented a CD band indicative of a preferential helical sense (Figure 1c).

Table 1. Polymerization of monomers 1-11 in water ${ }^{a}$

\begin{tabular}{|lllll|}
\hline no. & catalyst & yield & $\mathrm{Mw}^{b}$ & $\mathrm{Mw} / \mathrm{Mn}^{b}$ \\
\hline 1 & {$\left[\mathrm{Rh}(\operatorname{cod})_{2}\right]^{+} \mathrm{BF} 4 / \mathrm{HCl}$} & 73 & 79700 & 2.83 \\
\hline 2 & {$\left[\mathrm{Rh}(\operatorname{cod})_{2}{ }^{+} \mathrm{BF} 4 / \mathrm{HCl}\right.$} & 81 & 177000 & 2.36 \\
\hline 3 & {$\left[\mathrm{Rh}(\operatorname{cod})_{2}{ }^{+} \mathrm{BF} 4 / \mathrm{HCl}\right.$} & 76 & 111300 & 3.55 \\
\hline 4 & {$\left[\mathrm{Rh}(\operatorname{cod})_{2}\right]^{+} \mathrm{BF} 4 / \mathrm{HCl}$} & 85 & 217200 & 3.20 \\
\hline 5 & {$\left[\mathrm{Rh}(\operatorname{cod})_{2}\right]^{+} \mathrm{BF} 4 / \mathrm{HCl}$} & 78 & 163200 & 2.91 \\
\hline 6 & {$\left[\mathrm{Rh}(\operatorname{cod})_{2}\right]^{+} \mathrm{BF} 4 / \mathrm{HCl}$} & 80 & 119700 & 1.65 \\
\hline 7 & {$\left[\mathrm{Rh}(\operatorname{cod})_{2}{ }^{+} \mathrm{BF} 4 / \mathrm{HCl}\right.$} & 88 & 149400 & 2.38 \\
\hline 8 & {$\left[\mathrm{Rh}(\operatorname{cod})_{2}{ }^{+} \mathrm{BF} 4 / \mathrm{HCl}\right.$} & 70 & 138200 & 1.78 \\
\hline 9 & {$\left[\mathrm{Rh}(\operatorname{cod})_{2}\right]^{+} \mathrm{BF} 4 / \mathrm{HCl}$} & 65 & 145000 & 2.08 \\
\hline 10 & {$\left[\mathrm{Rh}(\operatorname{cod})_{2}{ }^{+} \mathrm{BF} 4 / \mathrm{HCl}\right.$} & 61 & 176500 & 1.53 \\
\hline 11 & {$\left[\mathrm{Rh}(\operatorname{cod})_{2}\right]^{+} \mathrm{BF} 4 / \mathrm{HCl}$} & 59 & 5779 & 1.21 \\
\hline
\end{tabular}

${ }^{a} 1$ equiv of $\mathrm{HCl}$ was added to the monomer solution to obtain the ammoniun salt. Polymerizations were carried out in water at room temperature for $36 \mathrm{~h},[\mathrm{M}]_{0}=0.5 \mathrm{M}$, [cat $]=0.05 \mathrm{M} .{ }^{b}$ Determined by SEC in a water solution of $\left[\mathrm{NaNO}_{3}\right]=0.05 \mathrm{M}$.

These polymers showed high stability in comparison to their lipophilic analogues, ${ }^{53}$ remaining the CD spectra of their solutions unaffected for at least one month. In addition, $\mathrm{pH}$ dependence experiments revealed that these PPAs are very stable in water in a wide range of $\mathrm{pH}$ values (from 1 to 10, Figure 2 and Figure S48). 
In general CD spectra of amino-PPAs is more intense in acid media ( $\mathrm{pH} 1-5)$, being reduced at neutral or basic $\mathrm{pH}$ (7-10) (Figure 2a-b and Figure S48). This fact indicates that the presence of ammonium cations in the pendants stabilize a preferred helical structure, which gradually diminishes when the $\mathrm{pH}$ increases.
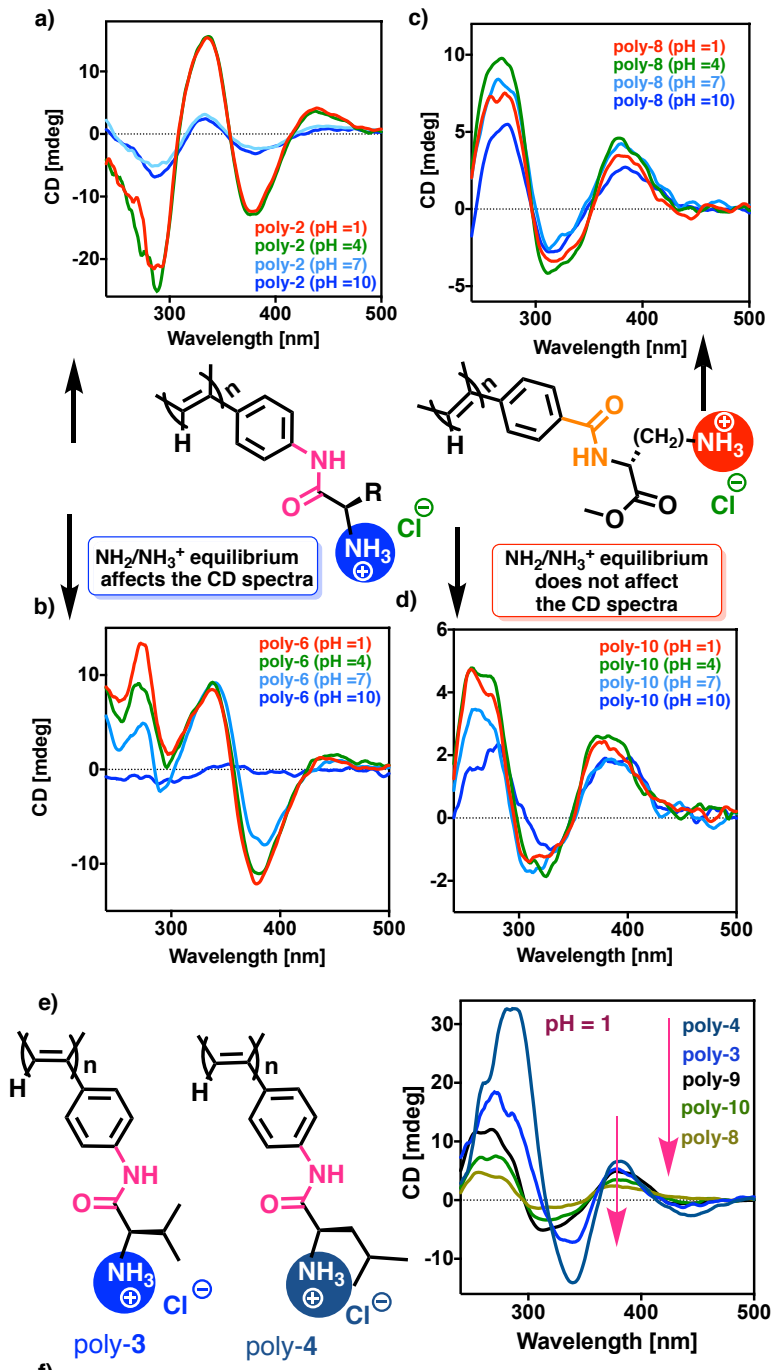

f)
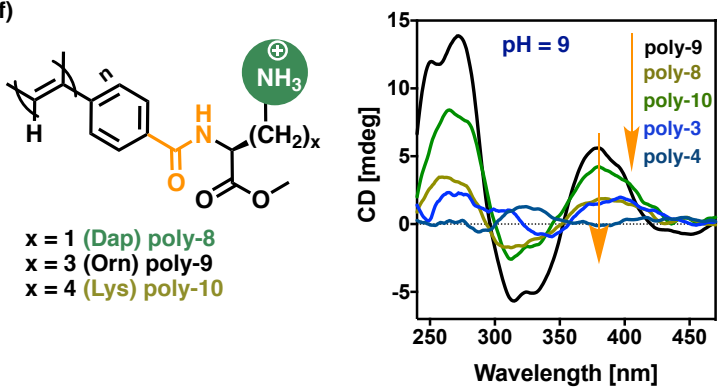

Figure 2. $\mathrm{pH}$-dependence studies in amino-PPAs bearing the amino group directly linked $(\mathrm{a}, \mathrm{b})$ to the chiral center or placed in a remote position (c,d) from the chiral center. Effect of the amino group (e) directly linked to the chiral center or (f) place in a remote position of a chiral PPA.
Moreover, these titration studies also revealed a direct relationship between the location of the amino group in the pendant and the effect of its protonation/deprotonation on the helical backbone, as depicted by its CD signature. It was found that those PPAs with the amino group directly linked to the chiral center, showed a high dependence, reaching a very ordered helix under protonation - see Figure 2a for poly-2 and Figure $2 \mathrm{~b}$ for poly-6 (see Figure S48) - . For their part, the PPAs with the amino group at a remote position-poly-(8-10) - showed a very low dependence with the $\mathrm{pH}$ (Figure $2 \mathrm{c}$ for poly-8 and 2d for poly-10, see Figure S48 for poly-9). In addition to the different sensitivity towards $\mathrm{pH}$ changes, we found that the intensity of the helical preference in amino PPAs depends also on the position of the amino group. Thus, at $\mathrm{pH}=1$, where the amino group should be protonated $\left(\mathrm{NH}_{3}{ }^{+}\right)$, the $\mathrm{CD}$ is stronger for poly-3 and poly-4 - amino group directly linked to the chiral center- than in poly-(8-10) - amino group placed in a remote position respect to the chiral center- (Figure $2 \mathrm{e}$ ). On the other hand, at $\mathrm{pH}=9$, when the amino group is in its neutral form, the CD spectra show lower intensity CD traces in all cases, being almost null for those where the amino group is directly linked to the chiral center. This fact indicates that in the absence of cationic groups; all amino substituted PPAs have a low helical preference (Figure 2f).

At this point, we reasoned that the helical sense induction observed in amino-PPAs after protonation could occur via two possible mechanisms: 1.- electrostatic repulsion between positive charges, or 2.- transmission to the polyenic skeleton of the variations in the conformational composition induced by changes on the $\mathrm{NH}_{2} / \mathrm{NH}_{3}{ }^{+}$equilibrium.

In the first case, the presence of positively charged amino groups should produce repulsions between pendants along the polymer chain, which could favor the adoption of a single handed helical structure. This mechanism is similar to the one described by Kakuchi and coworkers of PPAs bearing negatively charged pendant groups. ${ }^{54-56}$ On the other hand, the second mechanism correlates the helical induction of the PPA with conformational changes at the pendant group, concept that has been previously demonstrated in other PPAs. ${ }^{16-22}$

Studies to discern between these two mechanisms are described below.

\section{Dynamic behavior of amino-PPAs: stimuli-responsive studies}

In general, PPAs are well known to respond by changing helical parameters (helical sense or elongation) to external stimuli that produce variations on the conformational composition of the pendants. ${ }^{17-25}$ Therefore, we decided to examine the stimuli-response behavior of chiral 
amino-PPAs [poly-(2-10)- $\mathrm{H}^{+}$], using solvent polarity and metal ions as external stimuli. Solvent polarity changes and/or complexation with metal ions are expected to alter the conformational composition around the amino acid chiral center. These conformational changes are transmitted to the helical skeleton as helix amplification, helix inversion or changes in the elongation of the polyene backbone.

Thus, to perform these studies, PPAs poly-(2-10)- $\mathrm{H}^{+}$ were classified into two major groups attending to the position of the amino group within the pendant: 1.PPAs bearing the amino group directly linked to the chiral center [poly-(2-7)- $\left.\mathrm{H}^{+}\right]$and 2.- PPAs with the amino group placed at a remote position from chiral center [poly-(8-10) $\left.-\mathrm{H}^{+}\right]$.

First, solvent effects analysis on amino PPAs were carried out. Thus, [poly-(2-10)- $\mathrm{H}^{+}$] were dissolved in $\mathrm{MeOH}$ and DMSO. In most cases, the helical sense is not affected by changes in the solvent [poly-2- $\mathrm{H}^{+}$, poly-(5-6) $\mathrm{H}^{+}$ and poly- $(8-10)-\mathrm{H}^{+}$, see Figure $3 \mathrm{~b}$ for poly-(5-6)- $\mathrm{H}^{+}$and Figure S46 for the rest], which indicates that the helical induction mechanism should be produced by repulsions between positive charges (mechanism 1).

Nevertheless, in the special case of poly-3, poly-4, and poly-7, a helical inversion was observed from the water to the organic solvents $(\mathrm{MeOH}$ and DMSO) solutions (Figure 3a for poly-(3-4) and Figure S46 for poly-7). These results indicate that the helix inversion should be produced due to a conformational change at the pendant group (mechanism 2). Hence, in order to furhter elucidate the mechanisms of chiral induction in these polymers, $\mathrm{CD}$ studies in different water/ $\mathrm{MeOH}$ mixtures were done (Figure 3c). These studies shown a gradual and dependent change of the CD spectra with the water/ $\mathrm{MeOH}$ ratio, expected for equilibrium between two conformers at the pendant (mechanism 2).

\section{Conformational studies}

First, the conformational composition for poly-(8-10) was analyzed. Their chemical structures resemble those previously reported for PPAs bearing methyl ester amino acids, ${ }^{16,19}$ which are known to have a preferred syn conformation between the amide and the ester group at the pendant moiety in polar solvents such as DMSO or $\mathrm{MeOH}$ (Figure 4a). When the CD spectra for [poly-(810) $-\mathrm{H}^{+}$] in DMSO was compared to those obtained for other PPAs bearing methyl ester amino acids, similar CD spectra were observed indicating, therefore, the presence of a major syn conformation in these polymers (Figure $4)$.
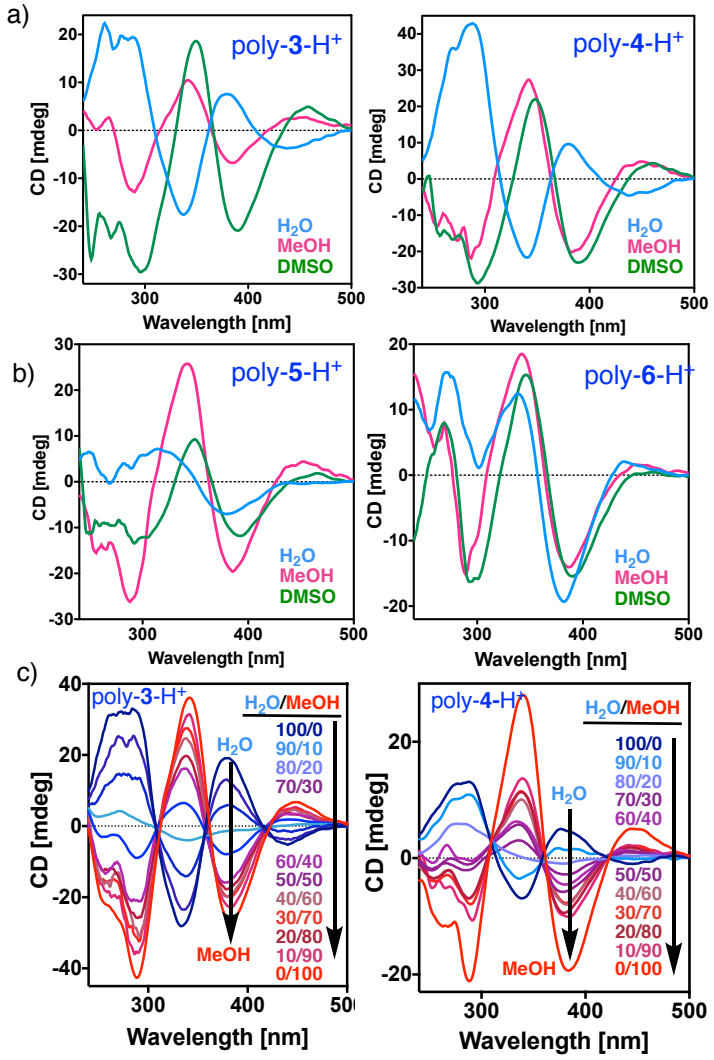

Figure 3. Amino-PPAs showing a (a) helix inversion (poly3 , poly-4), or (b) retention of the helical sense in water or highly polar organic solvent (poly-5-6). c) CD studies of poly-3 and poly-4 at different water $/ \mathrm{MeOH}$ mixtures $(\mathrm{pH}=4.5)$. [amino-PPA] $=0.5 \mathrm{mg} / \mathrm{mL}$

Thus, a preferred $s p$ conformation (carbonyl and ammonium group synperiplanar oriented) should be found at the pendant group in polar organic solvents $-\mathrm{MeOH}$ and $\mathrm{DMSO}-$ (Figure $4 \mathrm{~b}$ ), where the $R$ group is pointing backwards, opposite to the preferred syn conformer obtained for [poly- $(\mathbf{8}-10)-\mathrm{H}^{+}$] [opposite $\mathrm{CD}$ signatures for [poly-(2-7)- $\mathrm{H}^{+}$and poly-(8-10)- $\left.\mathrm{H}^{+}\right]$.

For its part, poly-2- $\mathrm{H}^{+}$and poly-(5-6)- $\mathrm{H}^{+}$retain this $s p$ conformation as the preferred one in water (see Figure $4 \mathrm{c}$ for poly-2- $\mathrm{H}^{+}$and Figure S46 for the others), while poly-(3-4)- $\mathrm{H}^{+}$and poly-7- $\mathrm{H}^{+}$suffer a conformational change detected by helix inversion on their CD spectra (see Figure 4c for poly-3- $\mathrm{H}^{+}$and Figure S46 for the rest). Therefore, in these polymers a major ap conformation at the pendant group - carbonyl and ammonium groups antiperiplanar oriented - should be stabilized in water (Figure 4b).

To verify the presence of this conformational equilibrium, and the most stable conformer in both, water and polar organic solvents, complexation studies with metal ions were carried out. Different metal perchlorate salts such as $\mathrm{AgClO}_{4}, \mathrm{KClO}_{4}, \mathrm{Co}\left(\mathrm{ClO}_{4}\right)_{2}$ and $\mathrm{Cu}\left(\mathrm{ClO}_{4}\right)_{2}$, were used to chelate the carbonyl and amino group, which 
stabilizes the $s p$ conformation at the pendant. To perform these studies is necessary to take into account that the $\mathrm{pH}$ of the solution will affect to the coordination of the metal to the amino group. Thus, we decided to carry out these experiments at different $\mathrm{pH}(\mathrm{pH}=1,5$ and 7$)$.

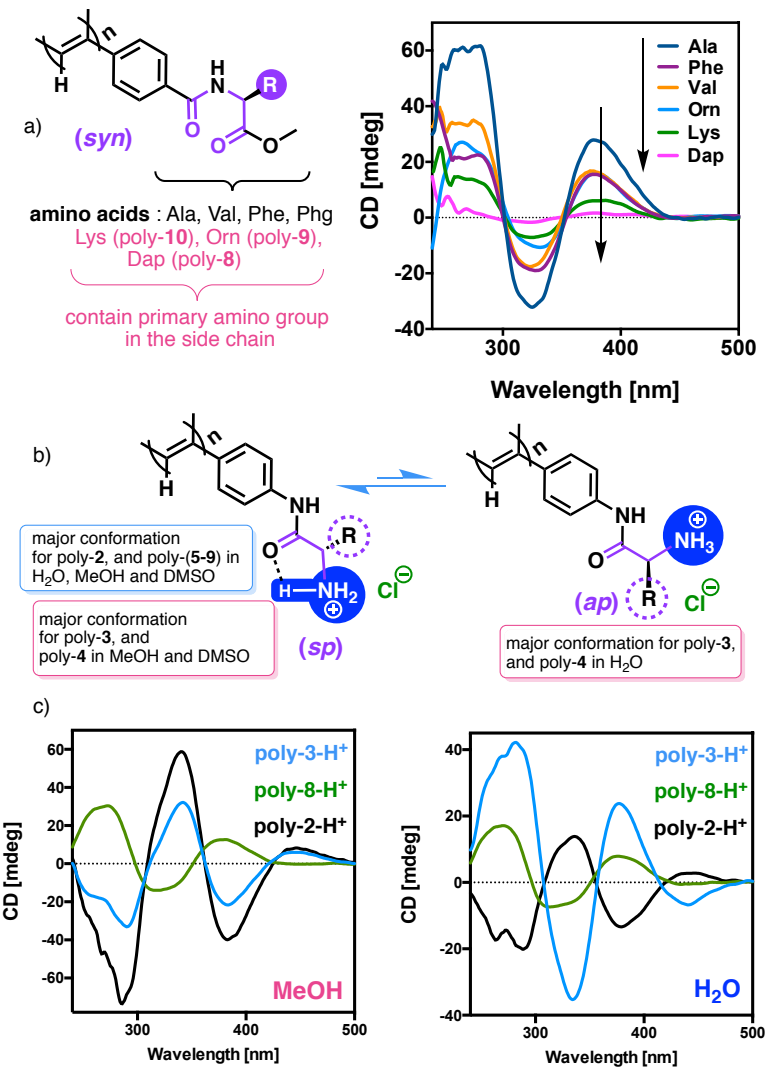

Figure 4. (a) Structure of PPA containing (L)-methyl ester aminoacids and their $\mathrm{CD}$ spectra in DMSO $(\mathrm{pH}=4.5)$. (b) Conformational composition on chiral amino-PPAs. (c) CD spectra of poly-2- $\mathrm{H}^{+}$, poly-3- $\mathrm{H}^{+}$and poly- $-\mathrm{H}^{+}$in $\mathrm{MeOH}$ and $\mathrm{H}_{2} \mathrm{O}(\mathrm{pH}=4.5)$. [amino-PPA] $=0.5 \mathrm{mg} / \mathrm{mL}$

As expected, no changes in the $\mathrm{CD}$ spectra were observed at $\mathrm{pH}=1-$ all of the amino groups are protonated-, while at higher $\mathrm{pH},(\mathrm{pH}=5,7$ or 10$)$ changes on the $\mathrm{CD}$ spectra were observed due to the chelation of the metal with the amino groups. In the case of poly- 2 and poly-(5-8) a helix enhancement is observed due to the further stabilization of the major $s p$ conformer (Figure 5 a for poly-2 and Figure S49), while a helix inversion is observed for poly-(3-4) and poly-7 due to a conformational change at the pendant moiety from the $a p$ to the $s p$ by chelation with the metal ions as inferred by IR spectroscopy (See Figure S49).

The dynamic behavior shown by poly-(3-4) and poly-7 through a helix inversion by adding metal ions or changing the solvent as external stimuli suggest us that this conformational equilibrium could also be tuned by changing the $\mathrm{NH}_{2} / \mathrm{NH}_{3}{ }^{+}$ratio.
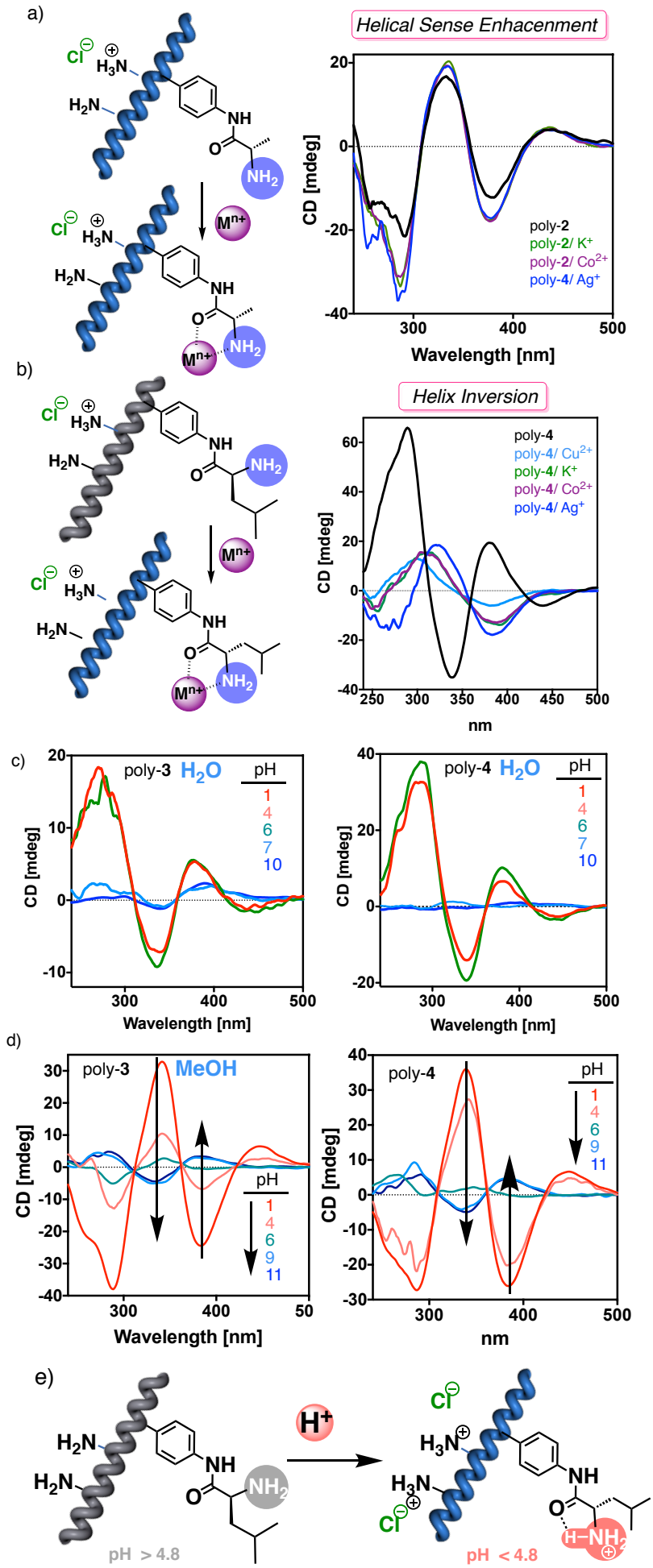

Figure 5. Interaction studies between (a) poly-2 and (b) poly-4 with metal ions in water at $\mathrm{pH}=7$ by $\mathrm{CD}$ spectroscopy. CD spectra for poly-3 and poly-4 at different $\mathrm{pH}$ in (c) water and (d) $\mathrm{MeOH}$, (e). Conformational composition of amino-PPAs in basic and acidic media. [amino-PPA] $=0.5$ $\mathrm{mg} / \mathrm{mL}$

In fact, $\mathrm{pH}$ titration studies carried out in water and described above, shown that the maximum helical pre- 
ponderance is obtained at $\mathrm{pH}=1$, while a clear decrease of the $\mathrm{CD}$ signal is produced when the $\mathrm{pH}$ increases (Figure 5c). Unfortunately, these studies cannot be performed at $\mathrm{pH}$ higher than 10 due to solubility problems, making not possible to invert the helical sense of the PPAs.

Nevertheless in $\mathrm{MeOH}$, these polymers [poly-(3-4)] are perfectly soluble in the $\mathrm{pH}$ range 1-11. As expected, these PPAs suffer helix inversion at $\mathrm{pH}>5$, indicating that at acidic $\mathrm{pH}$, poly-(3-4) adopt a preferred sp conformation stabilized by a $\mathrm{H}$-bond between the ammonium and the carbonyl groups, while a preferred ap conformation is stabilized at $\mathrm{pH}>5$, when the amino group is deprotonated (Figure 5d-e). Addition of metal ions in this deprotonated form of the amino group of poly-(3-4) confirm this conformation by producing a helix inversion on the CD spectra (see SI).

\section{CONCLUSIONS}

In conclusion, a straightforward protocol to obtain water-soluble primary/secondary amine containing helical PPAs in high yield and with high cis content of the conjugated double bonds is presented. This procedure consists on a slight variation of a previously reported polymerization protocol ${ }^{42-46}$. This protocol does not require any protection/deprotection steps.

This procedure has been shown to work within a library of 12 different amino-substituted phenylacetylenes. These PAs bears the amino group at different positions in the pendant, either directly linked to the chiral center or in a remote position.

It was found that these polymers present a dynamic helical structure in solution, which can be tuned by the $\mathrm{NH}_{2} / \mathrm{NH}_{3}{ }^{+}$ratio, solvent composition or the addition of metal ions. It is important to note that the location of the $\mathrm{NH}_{2} / \mathrm{NH}_{3}{ }^{+}$group in the pendant determines the mechanism of the helical response. Thus, when the amino group is directly connected to the chiral center, its protonation acts on the conformational equilibrium within the pendant, and therefore determines the resulting helical sense. On the contrary when the amino group is located in a remote position from the chiral center, its protonation does not modify the conformation of the pendant and therefore no helical changes are observed.

Overall, the easy preparation of the PPAs amines, their helical structure and properties opens a new horizon on their potential use in aqueous and biological media.

\section{ASSOCIATED CONTENT}

Supporting Information. Materials and methods, synthesis and characterization of monomers, synthesis and characterization of polymers and supporting references.

The Supporting Information is available free of charge on the ACS Publications website.

\section{AUTHOR INFORMATION}

\section{Corresponding Author}

felix.freire@usc.es, ricardo.riguera@usc.es

\section{ACKNOWLEDGMENT}

Financial support from MINECO (CTQ2014-61470-EXP, CTQ2015-70519-P), Xunta de Galicia (GRC2014/040, Centro singular de investigación de Galicia accreditation 20162019, ED431G/09) and the European Regional Development Fund (ERDF) is gratefully acknowledged. E. S. P. is grateful to MINECO for a FPU predoctoral fellowship.

\section{REFERENCES}

1) Freire, F.; Quiñoá, E.; Riguera, R. Chiral nanostructure in polymers under different deposition conditions observed using atomic force microscopy of monolayers: poly(phenylacetylene)s as a case study. Chem. Commun., 2017, 53, 481-492.

2) Van Leeuwen, T.; Heideman, H. G.; Zhao, D.; Wezenberg, S. J. ; Feringa, B. L. In situ control of polymer helicity with a non-covalently bound photoresponsive molecular motor dopant. Chem. Commun., 2017, 53, 6393-6396.

3) Wang, S.; Chen, J.; Feng, X.; Shi, G.; Zhang, J.; Wan, X. Conformation Shift Switches the Chiral Amplification of Helical Copoly(phenylacetylene)s from Abnormal to Normal "Sergeants-andSoldiers" Effect. Macromolecules, 2017, 50, 4610-4615.

4) Freire, F.; Quiñoá, E.; Riguera, R. Supramolecular Assemblies from Poly(phenylacetylene)s. Chem. Rev., 2016, 116, 1242-1271.

5) Freire, F.; Seco, J. M.; Quiñoá, E.; Riguera, R. Helical PolymerMetal Complexes: The Role of Metal Ions on the Helicity and the Supramolecular Architecture of Poly(phenylacetylene)s. Adv. Polym. Sci., 2013, 262, 123-140.

6) Yashima, E. Synthesis and structure determination of helical polymers. Polymer Journal 2010, 42, 3-16.

7) Yashima, E.; Maeda, K. Chirality-Responsive Helical Polymers. Macromolecules, 2008, 41, 3-12.

8) Percec, V.; Rudick, J. G.; Peterca, M.; Heiney, P. A. Nanomechanical Function from Self-Organizable Dendronized Helical Polyphenylacetylenes. J. Am. Chem. Soc., 2008, 130, 7503-7508.

9) Rudick, J. G.; Percec, V. Helical chirality in dendronized polyarylacetylenes. New J. Chem., 2007, 31, 1083-1096.

10) Yashima, E.; Ousaka, N.; Taura, D.; Shimomura, K.; Ikai, T.; Maeda, K. Supramolecular Helical Systems: Helical Assemblies of Small Molecules, Foldamers, and Polymers with Chiral Amplification and Their Functions. Chem. Rev., 2016, 116, 13752- 13990.

11) Yashima, E.; Maeda, K.; Furusho, Y. Single- and Double-Stranded Helical Polymers: Synthesis, Structures, and Functions. Acc. Chem. Res. 2008, 41, 1166-1180.

12) Yashima, E.; Maeda, K.; Lida, H.; Furusho, Y.; Nagai, K. Helical Polymers: Synthesis, Structures, and Functions. Chem. Rev. 2009, 109, 6102-6211.

13) Liu, J.; Lam, J. W. Y.; Tang, B. Z. Acetylenic Polymers: Syntheses, Structures, and Functions. Chem. Rev. 2009, 109, 5799-5867.

14) Rosen, B. M.; Wilson, C. J.; Wilson, D. A.; Peterca, M.; Imam, M. R.; Percec, V. Dendron-Mediated Self-Assembly, Disassembly, and Self-Organization of Complex Systems. Chem. Rev. 2009, 109, 62756540 .

15) Schwartz, E.; Koepf, M.; Kito, H. J.; Nolte, R. J. M.; Rowan, A. E. Helical poly(isocyanides): past, present and future. Polym. Chem. 2011, 2, 33- 47.

16) Alzubi, M.; Arias, S.; louzao, I.; Quiñoá, E.; Riguera, R.; Freire F. Multipodal dynamic coordination involving cation $-\pi$ interactions to control the structure of helical polymers. Chem. Commun. 2017, 53, 8573-8576. 
17) Arias, S.; Freire, F.; Calderón, M.; Bergueiro, J. Unexpected ChiroThermoresponsive Behavior of Helical Poly(phenylacetylene)s Bearing Elastin-Based Side Chains. Angew. Chem. Int. Ed., 2017, 56, 11420-11425.

18) Arias, S.; Freire, F.; Quiñoá, E.; Riguera, R. The leading role of cation $-\pi$ interactions in polymer chemistry: the control of the helical sense in solution. Polym. Chem., 2015, 6, 4725-4733.

19) Arias, S.; Núñez-Martinez, M.; Quiñoá, E.; Riguera, R.; Freire, F. A general route to chiral nanostructures from helical polymers: $P / M$ switch via dynamic metal coordination. Polym. Chem., 2017, 8, 3740-3745.

20) Rodríguez, R.; Arias, S.; Quiñoá, E.; Riguera, R.; Freire, F. The role of the secondary structure of helical poly(phenylacetylene)s in the formation of nanoparticles from polymer-metal complexes (HPMCs). Nanoscale, 2017, 8, 17752-17757.

21) Maeda, k.; Kamiya, N.; Yashima, E. Poly(phenylacetylene)s Bearing a Peptide Pendant: Helical Conformational Changes of the Polymer Backbone Stimulated by the Pendant Conformational Change. Chem. Eur. J. 2004, 10, 4000-4010.

22) Leiras, S.; Freire, F.; Seco, J. M.; Quiñoá, E.; Riguera, R. Controlled modulation of the helical sense and the elongation of poly(phenylacetylene)s by polar and donor effects. Chem. Sci. 2013, 4, 2735-2743.

23) Maeda, K.; Mochizuki, H.; Osato, K.; Yashima, E. StimuliResponsive Helical Poly(phenylacetylene)s Bearing Cyclodextrin Pendants that Exhibit Enantioselective Gelation in Response to Chirality of a Chiral Amine and Hierarchical Super-Structured Helix Formation. Macromolecules 2011, 44, 3217-3226.

24) Iida, H.; Miki, M.; Iwahana, S.; Yashima, E. Riboflavin-Based Fluorogenic Sensor for Chemo- and Enantioselective Detection of Amine Vapors. Chem. Eur. J. 2014, 20, 4257-4262.

25) Rodríguez, R.; Quiñoá, E.; Riguera, R.; Freire, F. Multistate Chiroptical Switch Triggered by Stimuli-Responsive Chiral Teleinduction. Chem. Mater. 2018, 30, 2493-2497.

26) Shimomura, K.; Ikai, T.; Kanoh, S.; Yashima, E.; Maeda, K. Switchable enantioseparation based on macromolecular memory of a helical polyacetylene in the solid state. Nat. Chem., 2014, 6, 429-434.

27) Iida, H.; Tang, Z.; Yashima, E. Synthesis and bifunctional asymmetric organocatalysis of helical poly(phenylacetylene)s bearing cinchona alkaloid pendants via a sulfonamide linkage. J. Polym. Sci., Part A: Polym. Chem. 2013, 51, 2869-2879.

28) Tang, Z.; Iida, H.; Hu, H.-Y.; Yashima, E. Remarkable Enhancement of the Enantioselectivity of an Organocatalyzed Asymmetric Henry Reaction Assisted by Helical Poly(phenylacetylene)s Bearing Cinchona Alkaloid Pendants via an Amide Linkage. ACS Macro Lett. 2012, 1, 261-265.

29) Okoshi, K.; Sakurai, S.; Ohsawa, J. K.; Yashima, E. TwoDimensional Hierarchical Self-Assembly of One-Handed Helical Polymers on Graphite. Angew. Chem., Int. Ed. 2006, 45, 1245

30) Sakurai, S.-I.; Okoshi, K.; Kumaki, J.; Yashima, E. TwoDimensional Surface Chirality Control by Solvent-Induced Helicity Inversion of a Helical Polyacetylene on Graphite. J. Am. Chem. Soc. 2006, 128, 5650-5651.

31) Percec, V.; Rudick, J. G.; Wagner, M.; Obata, M.; Mitchell, C. M.; Cho, W.-D.; Magonov, S. N. AFM Visualization of Individual and Periodic Assemblies of a Helical Dendronized Polyphenylacetylene on Graphite. Macromolecules, 2006, 39, 7342-7351.

32) Rodríguez, R.; Ignés-Mullol, J.; Sagués, F.; Quiñoá, E., Riguera, R.; Freire, F. Nanoscale, 2016, 8, 3362-3367

33) Yoshida, Y.; Mawatari, Y.; Motoshige, A.; Motoshige, R.; Hiraoki, T.; Wagner, M.; Müllen, K.; Tabata, M. Accordion-like Oscillation of Contracted and Stretched Helices of Polyacetylenes Synchronized with the Restricted Rotation of Side Chains. J. Am. Chem. Soc. 2013, 135, 4110-4116

34) Liu, L.; Namikoshi, T.; Zang, Y.; Aoki, T.; Hadano, Sh.; Abe, Y.; Wasuzu, I.; Tsutsuba, T.; Teraguchi, M.; Kaneko, T. “Top-Down Preparation of Self-Supporting Supramolecular Polymeric Membranes Using Highly Selective Photocyclic Aromatization of Cis-Cisoid
Helical Poly(phenylacetylene)s in the Membrane State". J. Am. Chem. Soc., 2013, 135, 602-605.

35) Nieto-Ortega B.; Rodríguez, R.; Medina, S.; Quiñoá, E., Riguera, R.; Casado, J.; Freire, F.; Ramírez, J. Sequential Induction of Chirality in Helical Polymers: From the Stereocenter to the Achiral Solvent $J$. Phys. Chem. Lett. 2018, 9, 2266-2270.

36) Fernandez, B.; Rodríguez, R.; Rizzo, A.; Quiñoá, E.; Riguera, R.; Freire, F. Predicting the Helical Sense of Poly(phenylacetylene)s from their Electron Circular Dichroism Spectra. Angew. Chem., Int. Ed. 2018, 57, 3666.

37) Rodríguez, R.; Quiñoá, E.; Riguera, R.; Freire, F. Architecture of Chiral Poly(phenyl acetylene)s: From Compressed/Highly Dynamic to Stretched/Quasi-Static Helices". J. Am. Chem. Soc., 2016, 138, 9260-9268.

38) Miyagawa, T.; Yamamoto, M.; Muraki, R.; Onouchi, H.; Yashima, E. Supramolecular Helical Assembly of an Achiral Cyanine Dye in an Induced Helical Amphiphilic Poly(phenylacetylene) Interior in Water. J. Am. Chem. Soc. 2007, 129, 3676-3682

39) Nagai, K.; Maeda, K.; Takeyama, Y.; Sato, T.; Yashima, E. Temperature-Induced Chiroptical Changes in a Helical Poly(phenylacetylene) Bearing N,N-Diisopropylaminomethyl Groups with Chiral Acids in Water. Chem. Asian J. 2007, 2, $1314-1321$

40) Maeda, K.; Morino, K.; Okamoto, Y.; Sato, T.; Yashima, E. Mechanism of Helix Induction on a Stereoregular Poly((4carboxyphenyl)acetylene) with Chiral Amines and Memory of the Macromolecular Helicity Assisted by Interaction with Achiral Amines. J. Am. Chem. Soc. 2004, 126, 4329-4342.

41) Ishikawa, M.; Maeda, K.; Mitsutsuji, Y.; Yashima, E. An Unprecedented Memory of Macromolecular Helicity Induced in an Achiral Polyisocyanide in Water. J. Am. Chem. Soc. 2004, 126, 732-733.

42) Yuan, W. Z.; Tang, L.; Zhao, H.; Jin, J. K.; Sun, J. Z.; Qin, Anjun; Xu, H. P.; Liu, J.; Yang, F.; Zheng, Q.; Chen, E.; Tang, B. Z. Direct Polymerization of Highly Polar Acetylene Derivatives and Facile Fabrication of Nanoparticle-Decorated Carbon Nanotubes. Macromolecules 2009, 42, 52-61.

43) Liu, J.; Lam, J. W. Y.; Tang, B. Z. Synthesis and Functionality of Substituted Polyacetylenes. In Design and Synthesis of Conjugated Polymers; Leclerc, M.; Morin, J.-F., $\quad$ Eds.; Wiley-VCH: Weinheim, Germany, 2010; pp 1- 43.

44) Saito, M. A.; Maeda, K.; Onouchi, H.; Yashima, E. "Synthesis and Macromolecular Helicity Induction of a Stereoregular Polyacetylene Bearing a Carboxy Group with Natural Amino Acids in Water", Macromolecules, 2000, 33, 4616-4618.

45) Maeda, K.; Goto, H.; Yashima, E. "Stereospecific Polymerization of Propiolic Acid with Rhodium Complexes in the Presence of Bases and Helix Induction on the Polymer in Water", Macromolecules, 2001, 34, 1160-1164.

46) Onouchi, H.; Hasegawa, T.; Kashiwagi, D.; Ishiguro, H.; Maeda, K.; Yashima, E. "Helicity Induction in Charged Poly(phenylacetylene)s Bearing Various Acidic Functional Groups in Water and Its Mechanism", 2005, 38, 8625-8633.

47) Subramanyam, S.; Blumstein, A. Conjugated ionic polyacetylenes. 5. Spontaneous polymerization of 2-ethynylpyridine in a strong acid. Macromolecules 1992, 25, 4058-4064.

48) Liu, R.; Sanda, F.; Masuda, T. Synthesis and properties of ornithine- and lysine-based poly(N-propargylamides). Responsiveness of the helical structure to acids, Polymer, 2007, 48, 6510-6518.

49) Saeed, I. , Khan, F. Z., Shiotsuki, M. and Masuda, T. Synthesis and properties of carbamate- and amine-containing poly(phenylacetylenes). J. Polym. Sci. A Polym. Chem., 2009, 47, 18531863.

50) Yashima, E; Maeda, Y.; Matsushima, T.; Okamoto, Y. Preparation of polyacetylenes bearing an amino group and their application to chirality assignment of carboxylic acids by circular dichroism. Chirality, 1997, 9, 593-600.

51) Kawamura, H.; Takeyama, Y.; Yamamoto, M.; Kurihara, H.; Morino, K.; Yashima, E. Chirality responsive helical 
poly(phenylacetylene) bearing L-proline pendants. Chirality, 2011, 23, E35-E42.

52) Maeda, K.; Okada, S.; Yashima, E; Okamoto, Y. Helix formation of poly(phenylacetylene) derivatives bearing amino groups at the meta position induced by optically active carboxylic acids. J. Polym. Sci. A Polym. Chem., 2001, 39, 3180-3189.

53) Percec, V.; Rudick, J. G.; Aqad, E. Diminished Helical Character in Para-Substituted Cis-Transoidal Polyphenylacetylenes Due to Intramolecular Cyclization. Macromolecules 2005, 38, 7205-7206. 54) Sakai, R.; Barasa, E. B.; Sakai, N.; Sato, S.-I.; Satoh T., Kakuchi, T. Colorimetric Detection of Anions in Aqueous Solution Using Poly(phenylacetylene) with Sulfonamide Receptors Activated by Electron Withdrawing Group. Macromolecules, 2012, 45, 8221-8227. 55) Sakai, R.; Sakai, N.; Satoh, T.; Li, W.; Zhang, A.; Kakuchi, T. Strict Size Specificity in Colorimetric Anion Detection Based on Poly(phenylacetylene) Receptor Bearing Second Generation Lysine Dendrons, Macromolecules, 2011, 44, 4249-4257.

56) Sakai, R.; Okade, S.; Barasam E. B.; Kakuchi, R.; Ziabka, M.; Umeda, S.; Tsuda, K.; Satoh, T.; Kakuchi, T. Efficient Colorimetric Anion Detection Based on Positive Allosteric System of Urea-Functionalized Poly(phenylacetylene) Receptor. Macromolecules, 2010, 43, 74067411.

\section{TOC}

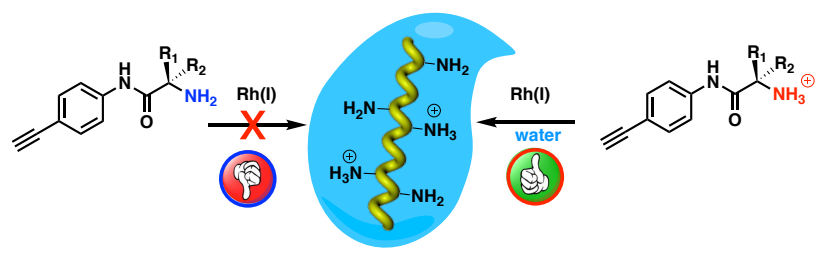


